\title{
PERIODIC HEAT TRANSFER IN FINS WITH VARIABLE THERMAL PARAMETERS
}

\author{
A. AzIz \\ Department of Mechanical Engineering, College of Engineering, \\ P.O. Box 800, Riyadh, Saudi Arabia \\ and \\ T. Y. NA \\ Department of Mechanical Engineering, University of Michigan-Dearborn, \\ Dearborn, MI 48128 , U.S.A.
}

(Received 3 October 1980 and in revised form 23 February 1981)

\begin{abstract}
Periodic heat transfer in a convecting fin with temperature dependent thermal conductivity and coordinate dependent heat transfer coefficient, is analyzed using a perturbation analysis. The zero-order problem, which corresponds to steady-state fin behaviour, is solved by quasilinearization. A method of complex combination is used, in conjunction with a noniterative numerical scheme, to solve the first-order and the second-order problems. The nonlinear nature of the problem gives rise to a nonoscillatory component in the second-order term, which causes a net change in the mean values of temperature and heat transfer rate. The direction of change depends on the thermal conductivity parameter $\alpha$. For $\alpha>0$, the mean temperature is increased, while the mean heat transfer rate is decreased. For $\alpha<0$, the effect is opposite. Detailed results showing the effects of various parameters on temperature distribution, heat transfer rate and time-averaging fin efficiency are presented and discussed.
\end{abstract}

\section{NOMENCLATURE}

$A$, constant defined by equation (35);

$b$, fin thickness;

$B, \quad$ dimensionless frequency, $\rho c \omega L^{2} / k_{a}$;

$c, \quad$ specific heat;

$f(X)$, function of $X$ defining coordinate dependence of $h$;

$h$, heat transfer coefficient;

$h_{b}$, heat transfer coefficient at the fin base;

$k$, thermal conductivity;

$k_{a}$, thermal conductivity at environment temperature;

$L, \quad$ fin length;

$N, \quad$ fin parameter, $\sqrt{ }\left(2 h_{b} / k_{a} b\right) L$;

$q$, heat transfer rate;

$Q$, dimensionless heat transfer rate, $q L / k_{a} b\left(T_{b m}-T_{a}\right)$;

$t, \quad$ time;

$T, \quad$ temperature;

$T_{b}, \quad$ fin base temperature;

$T_{a}, \quad$ environment temperature;

$T_{b m}$, mean fin base temperature;

$x$ axial distance;

$X$, dimensionless axial distance, $x / L$.

Greek symbols

c, dimensionless amplitudc of base temperature, equation (1);

$\alpha, \quad$ thermal conductivity parameter, $\beta$

$\left(T_{b m}-T_{a}\right)$;

$\beta, \quad$ slope of dimensionless thermal conductivity-temperature line;

$\rho, \quad$ density;

$\bar{\eta}, \quad$ time-average fin efficiency over a cycle; $\theta$ dimensionless temperature,

$\left(T-T_{a}\right) /\left(T_{b m}-T_{a}\right)$;

$0_{0}, \quad$ zero-order approximation;

$\theta_{1}, \quad$ first-order approximation;

$\theta_{2}, \quad$ second-order approximation;

$\theta_{2 s}, \quad$ nonoscillatory component of $\theta_{2}$;

$\phi, \quad$ complex function of $X$;

$\phi_{1}, \quad$ real part of $\phi$;

$\phi_{2}$, imaginary part of $\phi$;

$\psi, \quad$ complex function of $X$;

$\psi_{1}$, real part of $\psi$;

$\psi_{2}$, imaginary part of $\psi$;

$\tau, \quad$ dimensionless time, $k_{a} t / \rho c L^{2}$;

$\omega$, frequency of base temperature oscillation.

\section{INTRODUCTION}

ONE AREA of current interest in fin studies is the prediction of fin performance under periodic thermal conditions. Such conditions are often encountered in applications such as solar collectors, electronic cornponents, internal combustion engines, cutting tools etc. A recent paper of ours [1], and the references cited therein, give a fairly complete view of the work done so far. As such, no further review of the literature is attempted here.

The existing studies consider convecting, radiating and convecting-radiating fins with periodic variations of either base temperature or environment tempeiature or base heat flux or fluid temperature at the convectively cooled fin base. However, none of them takes into account the effect of variable thermal parameters which is always present in realistic situations. For example, in a convecting fin, the con- 
vective heat transfer coefficient varies considerably from the base to the tip [2]. Similarly, if large temperature differences exist, the dependence of fin thermal conductivity on temperature can be significant. It would seem that the study of periodic heat transfer in fins with variable thermal parameters is in order. The present paper covers this area.

To explore the effects of variable thermal parameters, we will consider a convecting fin (the effect of radiation, if any, is ignored) of uniform thickness with coordinate dependent heat transfer coefficient and temperature dependent thermal conductivity. The base temperature will be assumed to oscillate around a mean value. The heat transfer coefficient is allowed to vary along the fin length in an arbitrary manner. Its exact specification depends on the cooling process and the available experimental information. However, the thermal conductivity is assumed to have linear dependence on temperature. Such variations have been used for many years in steady fin problems, the most recent example being presented by Razelos and Imre [2].

A three-term perturbation analysis will be carried out in terms of the parameter $\therefore$, which represents the dimensionless amplitude of the base temperature oscillation. The zero-order problem, which is nonlinear as a result of temperature dependent thermal conductivity, corresponds to the steady-state behaviour. The first and the second order problems constitute two linear partial differential equations. With the use of method of complex combination, each is reduced to two, coupled linear boundary value problems which are finally integrated numerically by a noniterative procedure. The analysis highlights some interesting features associated with the nonlinear nature of the problem which otherwise remain obscure if a fully numerical approach is adopted. A second advantage of the procedure is that the computation is indeed very fast. A CPU time of $20 \mathrm{~s}$ was needed on Amdahl $470 \mathrm{~V} / 7$ system to compute all the data, only part of which appear in the present paper. Despite the retention of only three terms of the perturbation expansion, the solution is accurate up to $:=0.4$, a limit that is not likely to exceed in practice.

\section{ANALYSIS}

\section{Formulation}

For simplicity, we consider a straight fin of uniform thickness $b$ and length $L$ and assume the base temperature $T_{b}$ to oscillate around a mean value $T_{b m}$ with frequency $\omega$ according to

$$
T_{b}-T_{b m}=\left(T_{b m}-T_{a}\right) \& \cos \omega t \quad \delta<1 .
$$

The fin tip is taken to be adiabatic. On both lateral faces, the fin loses heat to an environment at temperature $T_{a}$ with heat transfer coefficient $h$, which is taken as a function of axial distance $x$. The thermal conductivity $k$ of the fin is assumed to vary linearly with temperature in accordance with usual practice, that is

$$
k=k_{a}\left[1+\beta\left(T-T_{a}\right)\right] .
$$

Based on one-dimensional conduction, the fin equations in dimensionless form appear as

$$
\begin{gathered}
\frac{\partial}{\partial X}\left[(1+\alpha \theta) \frac{\partial \theta}{\partial X}\right]-N^{2} f(X) \theta=\frac{\partial \theta}{\partial \tau} \\
X=0, \theta=1+\varepsilon \cos \beta \tau ; \quad X=1, \frac{\partial \theta}{\partial X}=0
\end{gathered}
$$

where the symbols are as defined in the Nomenclature.

\section{Perturbation solution}

Since : would in general remain below unity, we assume a regular perturbation expansion for $\theta$ in powers of $\varepsilon$ as

$$
\theta(X, \tau)=\theta_{0}(X)+\varepsilon \theta_{1}(X, \tau)+\varepsilon^{2} \theta_{2}(X, \tau)+\cdots .
$$

Substituting (5) into equations ( 3 ) and (4) and equating the coefficients of like powers of $\varepsilon$ on both sides of equations (3) and (4), one gets the following:

$$
\begin{gathered}
\varepsilon^{0}:\left(1+\alpha \theta_{0}\right) \theta_{0}^{\prime \prime}+\alpha \theta_{0}^{\prime 2}-N^{2} f(X) \theta_{0}=0 \\
X=0, \theta_{0}=1 ; \quad X=1, \theta_{0}^{\prime}=0 \\
\varepsilon^{1}: \frac{\partial}{\partial X}\left[\left(1+\alpha \theta_{0}\right) \frac{\partial \theta_{1}}{\partial X}+\alpha \theta_{0}^{\prime} \theta_{1}\right] \\
-N^{2} f(X) \theta_{1}=\frac{\partial \theta_{1}}{\partial \tau} \\
\varepsilon^{2}: \frac{\partial}{\partial X}\left[\left(1+\alpha \theta_{0}\right) \frac{\partial \theta_{2}}{\partial X}+\alpha \theta_{1} \frac{\partial \theta_{1}}{\partial X}+\alpha \theta_{0}^{\prime} \theta_{2}\right] \\
-N_{1}^{2} f(X) \theta_{2}=\frac{\partial \theta_{2}}{\partial \tau} \\
X=0, \theta_{2}=0 ; \quad X=1, \frac{\partial \theta_{2}}{\partial X}=0
\end{gathered}
$$

where the primes in equations (6)-(10) and all subsequent equations to follow, denote total differentiation with respect to $X$. Higher-order terms can be written similarly; however, the three-term expansion would be found sufficiently accurate up to $\varepsilon=0.4$. This limit is not likely to exceed in practical situations. In fact, in previous studies $[3,4]$, the maximum value assigned to $:$ was 0.2 .

The zero-order problem, described by equations ( 6 ) and (7), corresponds to the steady-state behaviour. Since no analytical solution is available, we shall solve it using quasilinearization in conjunction with the method of superposition [5].

To solve equations (8) and (9) we use the method of complex combination and assume a solution of the form

$$
\theta_{1}(X, \tau)=R[\phi(X) \exp (i B \tau)]
$$

where the operator $K$ represents the real part of the quantity in square brackets. With the use of (12) in equations (8) and (9), the governing equation for $\phi$ 
becomes

$\left(1+\alpha \theta_{0}\right) \phi^{\prime \prime}+2 \alpha \theta_{0}^{\prime} \phi^{\prime}+\left[\alpha \theta_{0}^{\prime \prime}-N^{2} f(X)-i B\right] \phi=0$

$$
X=0, \phi=1 ; \quad X=1, \phi^{\prime}=0 .
$$

By splitting $\phi$ into real and imaginary parts i.e.

$$
\phi=\phi_{1}+i \phi_{2}
$$

equations for $\phi_{1}$ and $\phi_{2}$ now constitute two, coupled linear boundary value problems as follows:

$$
\begin{aligned}
\left(1+\alpha \theta_{0}\right) \phi_{1}^{\prime \prime} & +2 \alpha \theta_{0}^{\prime} \phi_{1}^{\prime} \\
& +\left[\alpha \theta_{0}^{\prime \prime}-N^{2} f(X)\right] \phi_{1}+B \phi_{2}=0 \\
\left(1+\alpha \theta_{0}\right) \phi_{2}^{\prime \prime} & +2 \alpha \theta_{0}^{\prime} \phi_{2}^{\prime} \\
& +\left[\alpha \theta_{0}^{\prime \prime}-N^{2} f(X)\right] \phi_{2}-B \phi_{1}=0 \\
X=0, \phi_{1} & =1, \phi_{2}=0 ; X=1, \phi_{1}^{\prime}=\phi_{2}^{\prime}=0 .
\end{aligned}
$$

Being linear, equations (16)-(18) can be solved noniteratively by the method of superposition as detailed in [5].

Coming to the solution of equations (10) and (11), it is noted that one of the terms has $\theta_{1}\left(\partial \theta_{1} / \partial X\right)$ associated with it. Using equation (12) it can be shown, after some manipulation, that

$$
\theta_{1} \frac{\partial \theta_{1}}{\partial X}=\frac{1}{2}\left(\phi_{1} \phi_{1}^{\prime}+\phi_{2} \phi_{2}^{\prime}\right)+R\left[\left(z_{1}+i z_{2}\right) \mathrm{e}^{i 2 \theta r}\right]
$$

where

$$
\begin{aligned}
& z_{1}=\frac{1}{2}\left(\phi_{1} \phi_{1}^{\prime}-\phi_{2} \phi_{2}^{\prime}\right) \\
& z_{2}=\frac{1}{2}\left(\phi_{1} \phi_{2}^{\prime}+\phi_{2} \phi_{1}^{\prime}\right) .
\end{aligned}
$$

Equation (19) suggests that the solution for $\theta_{2}$ must be written as the sum of a nonoscillatory component $\theta_{2 s}$ and an oscillatory component, in the form

$$
\theta_{2}=\theta_{2 s}+R\left[\psi(X) \mathrm{e}^{i 2 B \tau}\right]
$$

Using equation (21) in equations (10) and (11) leads to the following system of equations for $\theta_{2 s}$ and $\psi$

$$
\begin{gathered}
\begin{array}{c}
\left(1+\alpha \theta_{0}\right) \theta_{2 s}^{\prime \prime}+2 \alpha \theta_{0}^{\prime} \theta_{2 s}^{\prime}+\alpha \theta_{0}^{\prime \prime} \theta_{2 s} \\
+\frac{1}{2} \alpha\left(\phi_{1} \phi_{1}^{\prime \prime}+\phi_{1}^{\prime 2}+\phi_{2} \phi_{2}^{\prime \prime}+\phi_{2}^{\prime 2}\right)-N^{2} f(X) \theta_{2 s} \\
=0
\end{array} \\
X=0, \theta_{2 s}=0 ; \quad X=1, \theta_{2 s}^{\prime}=0 \\
\left(1+\alpha \theta_{0}\right) \psi^{\prime \prime}+2 \alpha \theta_{0}^{\prime} \psi^{\prime}+\alpha\left(z_{1}^{\prime}+i z_{2}^{\prime}\right) \\
+\left[\alpha \theta_{0}^{\prime \prime}-N^{2} f(X)-i 2 B\right] \psi=0 \\
X=0, \quad \psi=0 ; \quad X=1, \psi^{\prime}=0
\end{gathered}
$$

where

$$
\begin{gathered}
z_{1}^{\prime}=\frac{1}{2}\left(\phi_{1} \phi_{1}^{\prime \prime}+\phi_{1}^{2}-\phi_{2} \phi_{2}^{\prime \prime}-\phi_{2}^{\prime 2}\right) \\
z_{2}^{\prime}=\frac{1}{2}\left(\phi_{1} \phi_{2}^{\prime \prime}+2 \phi_{1}^{\prime} \phi_{2}^{\prime}+\phi_{2} \phi_{1}^{\prime \prime}\right) .
\end{gathered}
$$

Once again splitting $\psi$ into real and imaginary parts i.e.

$$
\psi=\psi_{1}+i \psi_{2}
$$

we obtain equations for $\psi_{1}$ and $\psi_{2}$ as follows:

$$
\begin{aligned}
&\left(1+\alpha \theta_{0}\right) \psi_{1}^{\prime \prime}+2 \alpha \theta_{0}^{\prime} \psi_{1}^{\prime}+\alpha z_{1}^{\prime} \\
&+ {\left[\alpha \theta_{0}^{\prime \prime}-N^{2} f(X)\right] \psi_{1}+2 B \psi_{2}=0 } \\
&\left(1+\alpha \theta_{0}\right) \psi_{2}^{\prime \prime}+2 \alpha \theta_{0}^{\prime} \psi_{2}^{\prime}+\alpha z_{2}^{\prime} \\
&+ {\left[\alpha \theta_{0}^{\prime \prime}-N^{2} f(X)\right] \psi_{2}-2 B \psi_{1}=0 } \\
& X=0, \psi_{1}=\psi_{2}=0 ; \quad X=1, \psi_{1}^{\prime}=\psi_{2}^{\prime}=0 .
\end{aligned}
$$

As before, equations (22) and (23) and (29)-(31) are solved noniteratively with the aid of method of superposition. It should be emphasized that except for the solution of $\theta_{0}$, all other solutions are carried out noniteratively.

\section{RESULTS AND DISCUSSION}

\section{Temperature distribution}

The temperature distribution in terms of quantities determined numerically can be written as

$$
\begin{aligned}
\theta=\theta_{0} & +\varepsilon^{2} \theta_{2 s}+\varepsilon\left(\phi_{1} \cos B \tau-\phi_{2} \sin B \tau\right) \\
& +\varepsilon^{2}\left(\psi_{1} \cos 2 B \tau-\psi_{2} \sin 2 B \tau\right)+O\left(\varepsilon^{3}\right) .
\end{aligned}
$$

Equation (32) shows that the nonoscillatory component $\theta_{2 s}$, associated with the second-order term, causes a net change in the mean temperature, which in the absence of oscillation is simply $\theta_{0}$. For all parametric values of $N$ and $B$ used here, $\theta_{2 s}$ at all axial locations was always positive for $\alpha>0$, and negative for $\alpha<0$. This shows that if the thermal conductivity of the fin material increases with temperature $(\alpha>0)$, it causes the mean temperature to increase. On the other hand, if the thermal conductivity decreases with temperature $(\alpha<0)$, the result is a decrease in the mean temperature. This is a consequence of the nonlinearity due to temperature dependent thermal conductivity and is absent for constant thermal conductivity fin, where the mean values are not affected by base temperature oscillation [3]. However, in all cases considered herein, $\theta_{2 s}$ was an order of magnitude less than $\theta_{0}$ and therefore the net change in mean temperature is rather small.

It is interesting to point out that for constant thermal conductivity $(\alpha=0), \theta_{2 s}, \psi_{1}$ and $\psi_{2}$ are identically zero. In this case, the second and all the subsequent order terms of the perturbation series vanish and the two-term perturbation solution reproduces the exact solution of Yang [3]. The present numerical solutions for $\phi_{1}$ and $\phi_{2}$ agreed very well with the corresponding values derived from Yang's exact solution [3].

Another noteworthy feature of equation (32) is the presence of a second-order oscillatory component with twice the frequency of base temperature oscillation. As noted earlier, this also arises as a result of the nonlinearity due to temperature dependent thermal conductivity and does not exist for the constant thermal conductivity case.

To illustrate the effect of variable thermal conductivity, a typical set of temperature distribution is shown in Fig. 1. The data are for $N=1, B=1, \varepsilon=0.1$ 

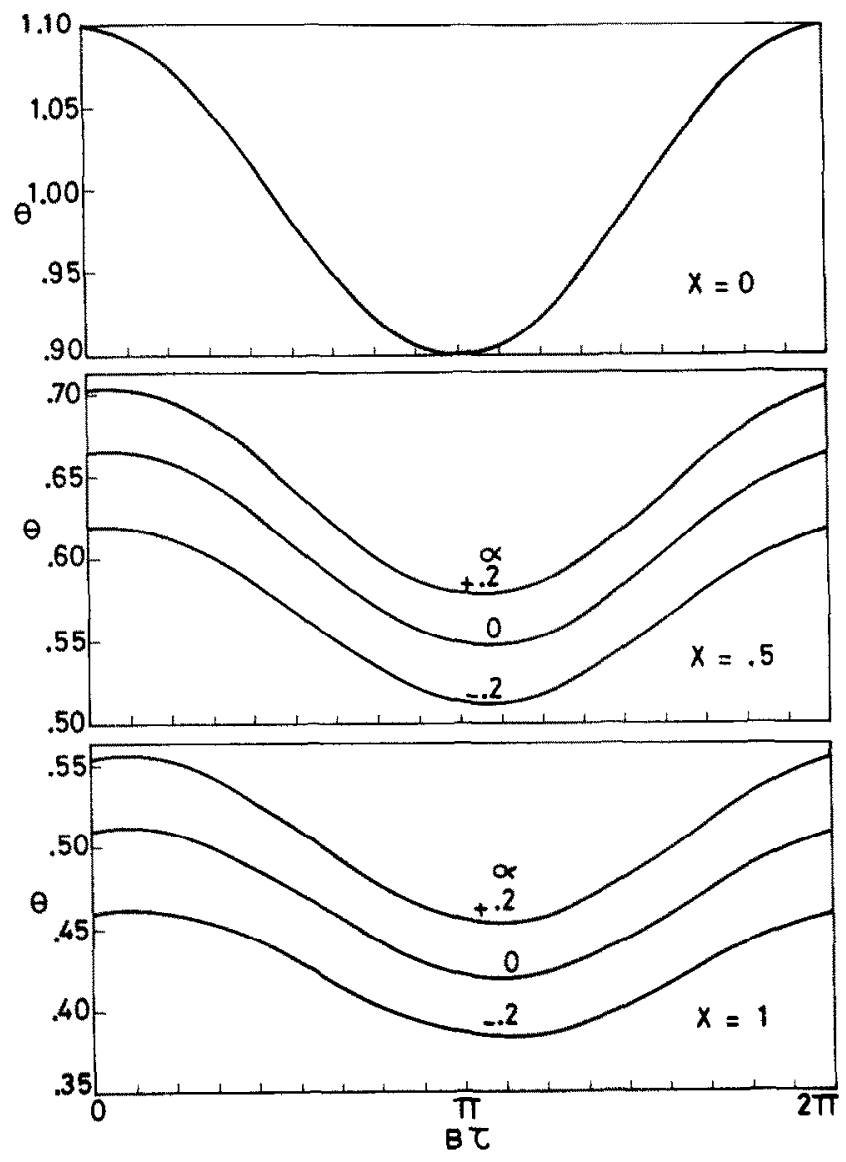

FIG. 1. Effect of $\alpha$ on temperature distribution; $N=1, B=1, \varepsilon=0.1, f(X)=\exp (X)$.

and exponential variation of heat transfer coefficient. Compared to $\alpha=0$, the temperature at any axial location is higher for $\alpha>0$ and lower for $\alpha<0$. Also noted is the fact that the amplitude of oscillation decreases and the phase angle increases as one goes along the fin. Comparison with the corresponding results for constant heat transfer coefficient shows that the temperature throughout the fin is lower for exponential variation. The phase angle is also comparatively smaller.

\section{Heat transfer rate}

Evaluating the temperature gradient from equation (32) the instantaneous heat transfer rate $Q$ can be derived as

$$
\begin{aligned}
-Q= & (1+\alpha) \theta_{0}^{\prime}(0)+\varepsilon^{2}(1+\alpha) \theta_{2 s}^{\prime}(0) \\
& +\delta\left\{\alpha \theta_{0}^{\prime}(0) \cos B \tau+(1+\alpha)\left[\phi_{1}^{\prime}(0)\right.\right. \\
& \left.\left.\times \cos B \tau-\phi_{2}^{\prime}(0) \sin B \tau\right]\right\} \\
& +\varepsilon^{2}\left\{(1+\alpha)\left[\psi_{1}^{\prime}(0) \cos 2 B \tau-\psi_{2}^{\prime}(0) \sin 2 B \tau\right]\right. \\
& \left.+\alpha \cos B \tau\left[\phi_{1}^{\prime}(0) \cos B \tau-\phi_{2}^{\prime}(0) \sin B \tau\right]\right\} \\
& +O\left(\varepsilon^{3}\right) \ldots
\end{aligned}
$$

The presence of the term $\varepsilon^{2}(1+\alpha) \theta_{2 s}(0)$ causes a net change in the mean heat transfer, which in the absence of oscillation is $(1+\alpha) \theta_{0}^{\prime}(0)$. Numerical computations showed that $\theta_{2 s}^{\prime}(0)$ is always positive for $\alpha>0$, and negative for $\alpha<0$. Since $\theta_{0}^{\prime}(0)$ is always negative, it implies that the mean heat transfer rate is decreased when the thermal conductivity increases with temperature $(\alpha>0)$, and increased when the thermal conductivity decreases with temperature $(\alpha<0)$. When $\alpha$ $=0$ (constant thermal conductivity) $\theta_{2 s}$ is identically zero and therefore the mean heat transfer rate is not affected by the base temperature oscillation. Also, the higher frequency term present for $\alpha \neq 0$ disappears for the linear case of $\alpha=0$.

It is significant to note that the term $\varepsilon^{2}(1+\alpha) \theta_{2 s}^{\prime}(0)$ can have substantial effect, particularly with the combination of low $N$ and high $B$. For example, with $N$ $=0.5, B=10$ and $\varepsilon=0.2$, the net change in the mean heat transfer rate is about $7.5 \%$ compared to no oscillation value.

Representative plots of instantaneous heat transfer rate are shown in Figs. 2 and 3. Figure 2 illustrates the effects of variable thermal conductivity at $B=1$ and $B$ $=10$, with $N=0.5, \varepsilon=0.2$ and $f(X)=1$. As expected, the average heat transfer rate, compared to the case of $\alpha=0$, is generally higher for $\alpha>0$ and lower for $\alpha<0$. At $B=1$, the amplitude of oscillation is small but 


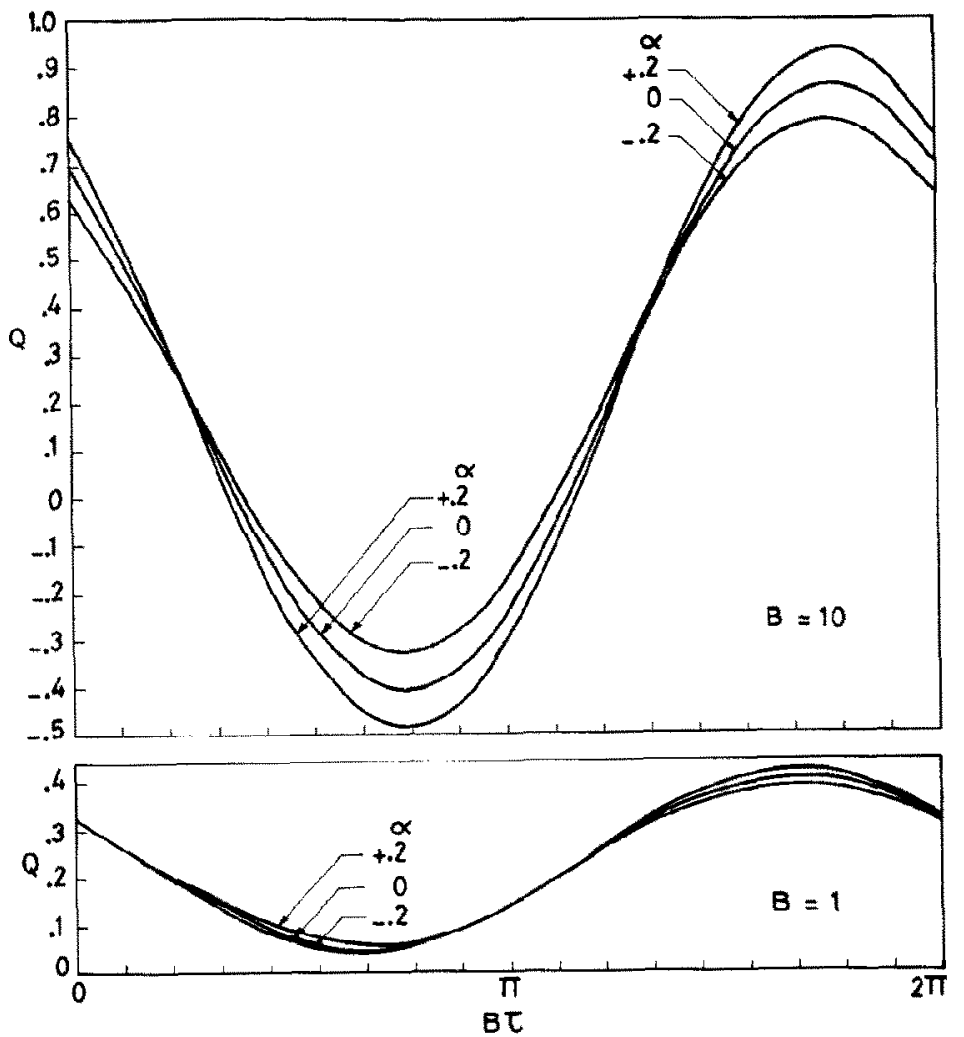

Fig. 2. Effect of parameters $\alpha$ and $B$ on instantaneous heat transfer rate; $N=0.5, k=0.2, f(X)=1$.

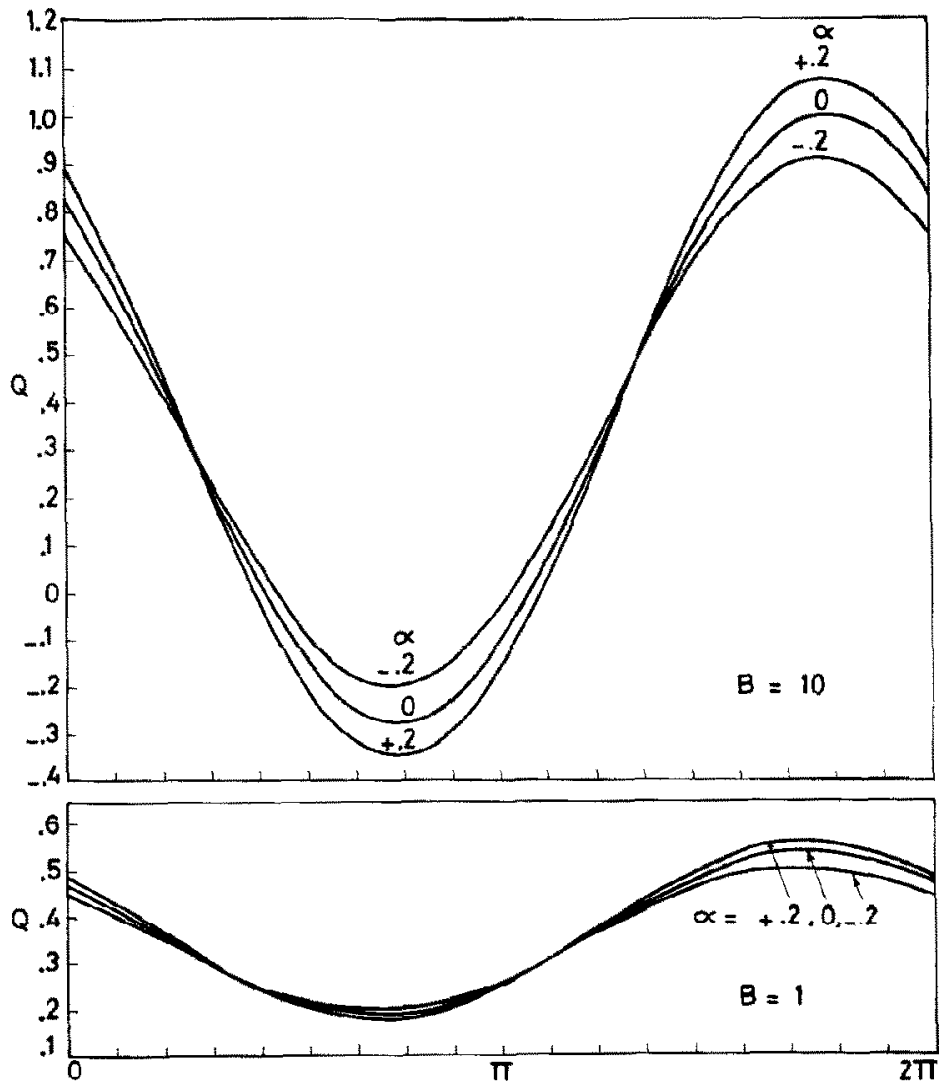

Fig. 3. Effect of parameters $x$ and $B$ on instantaneous heat transfer rate; $N=0.5, f=0.2, f(X)=\exp (X)$. 

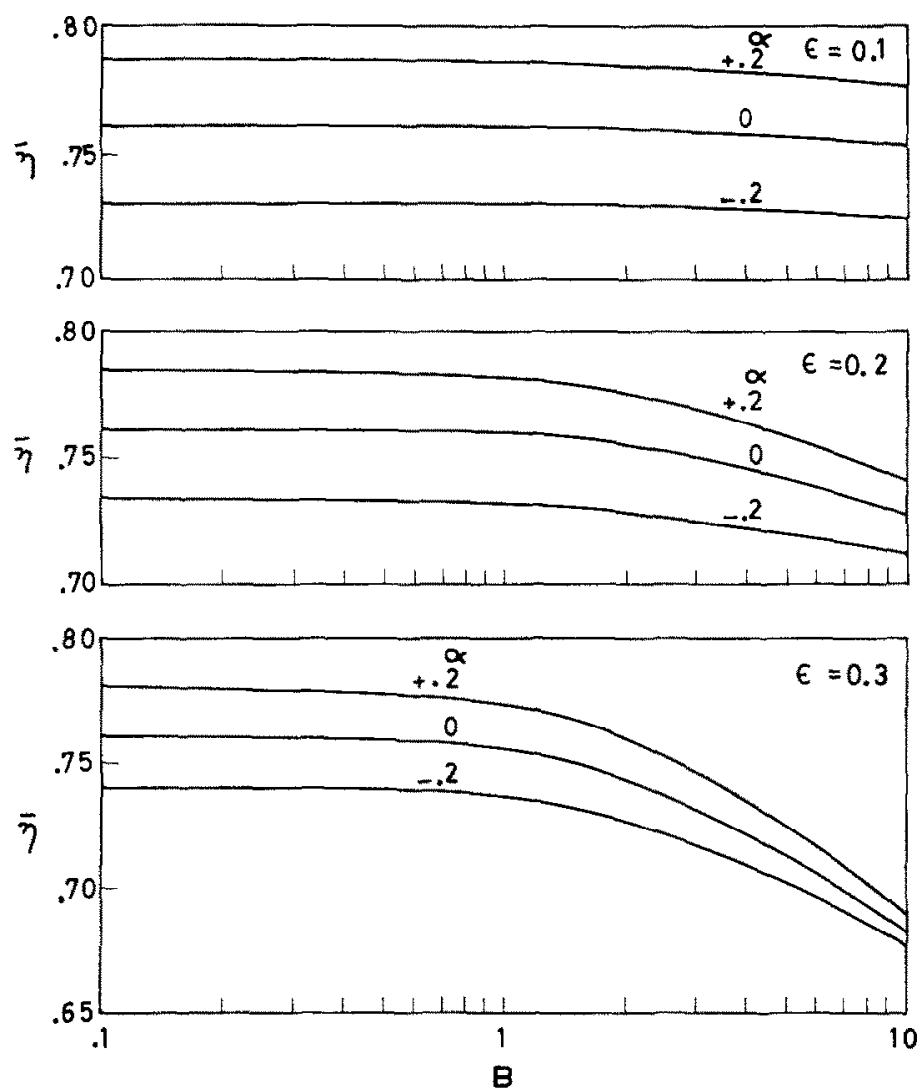

FIG. 4. Time-average fin efficiency: effects of $B . \alpha$ and $\varepsilon ; N=1, f(X)=1$.

increases quite rapidly as $B$ is increased to 10 . It is noted that the heat transfer rate always leads the base temperature. It is also interesting to note that at $B=1$, the heat transfer rate is positive throughout the cycle but at $B=10$ negative values occur for part of the cycle, indicating a reversal of heat flow. This reversed or back heat flow is more pronounced for $\alpha>0$. The fact that heat actually flows into the fin base for part of the cycle indicates a reduction in the overall heat rejection by the fin.

Figure 3 is the counterpart of Fig. 2 for the exponential variation of heat transfer coefficient, that is $f(X)=\exp (X)$. The characteristic features are the same except that the heat transfer rate is now higher and the reverse heat flow is reduced.

\section{Fin efficiency}

Instead of instantaneous fin efficiency, we study the effect of temperature oscillation on time-average fin efficiency, which is a more meaningful quantity. Over a cycle, the average fin efficiency $\bar{\eta}$ can be evaluated from $Q$ as follows:

$$
\bar{\eta}=\frac{1}{2 \pi N^{2} A} \int_{0}^{2 \pi} \frac{Q}{(1+\varepsilon \cos B \tau)} d(B \tau)
$$

where

$$
A=\int_{0}^{1} f(X) \mathrm{d} X
$$

The effect of parameters $\alpha$ and $\varepsilon$ on $\bar{\eta}$ are shown in Fig. 4 for $N=1$ and in Fig. 5 for $N=0.5$. At low values of $B, \bar{\eta}$ is very close to the usual steady-state value without oscillation. However, as $B$ increases, $\bar{\eta}$ diminishes quite rapidly particularly for higher values of $x$. Indeed, at $B=10$, the reduction is substantial. It is interesting to note in Fig. 5 that the curves for different $\alpha$ overlap at some intermediate value of $B$. Also, the reduction in $\bar{\eta}$ is more drastic at $N=0.5$ (Fig. 5) than for $N=1$ (Fig. 4).

Finally, we give Fig. 6 which is a counterpart of Fig. 5 for the case of $f(X)=\exp (X)$. Comparing Fig. 6 with Fig. 5 shows that with $f(X)=\exp (X)$ the reduction in $\bar{\eta}$ is less drastic than for $f(X)=1$. This again seems reasonable because the average heat transfer coefficient is now higher, and the effect of oscillation on $\bar{\eta}$ should be smaller as predicted by the exact solution with higher heat transfer coefficient [3].

It may seem questionable to use the perturbation solution up to $\varepsilon=0.3$ as done in Figs. 4-6. However, the fact that for $\alpha=0$, the two-term perturbation solution reproduces the exact solution would seem to indicate that the accuracy holds up even beyond $\varepsilon$ $=0.3$.

\section{CONCLUDING REMARKS}

The present analysis is based on three assumptions namely: (a) one-dimensional conduction; (b) no tip 

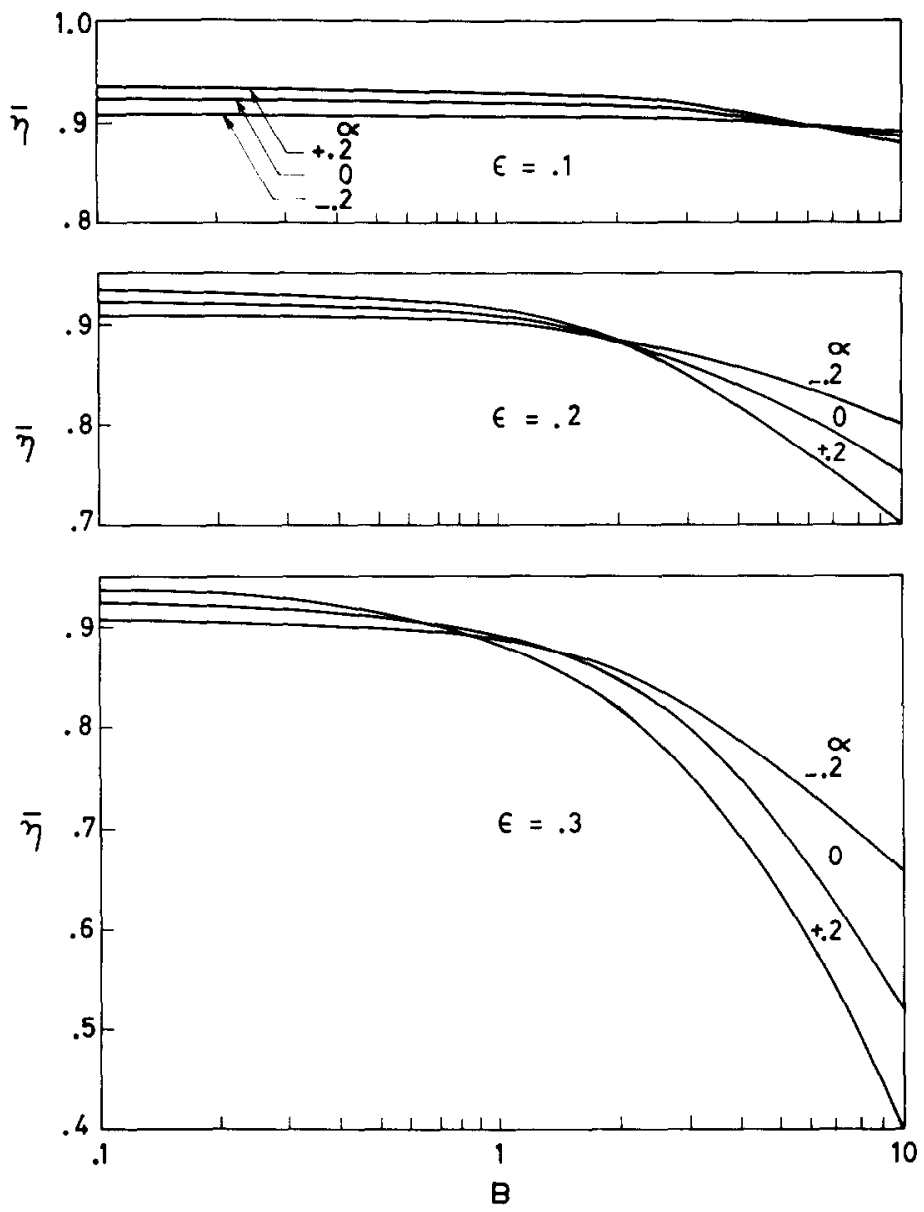

Fig. 5. Time-average fin efficiency: effects of $B, \alpha$ and $\varepsilon ; N=0.5, f(X)-1$.
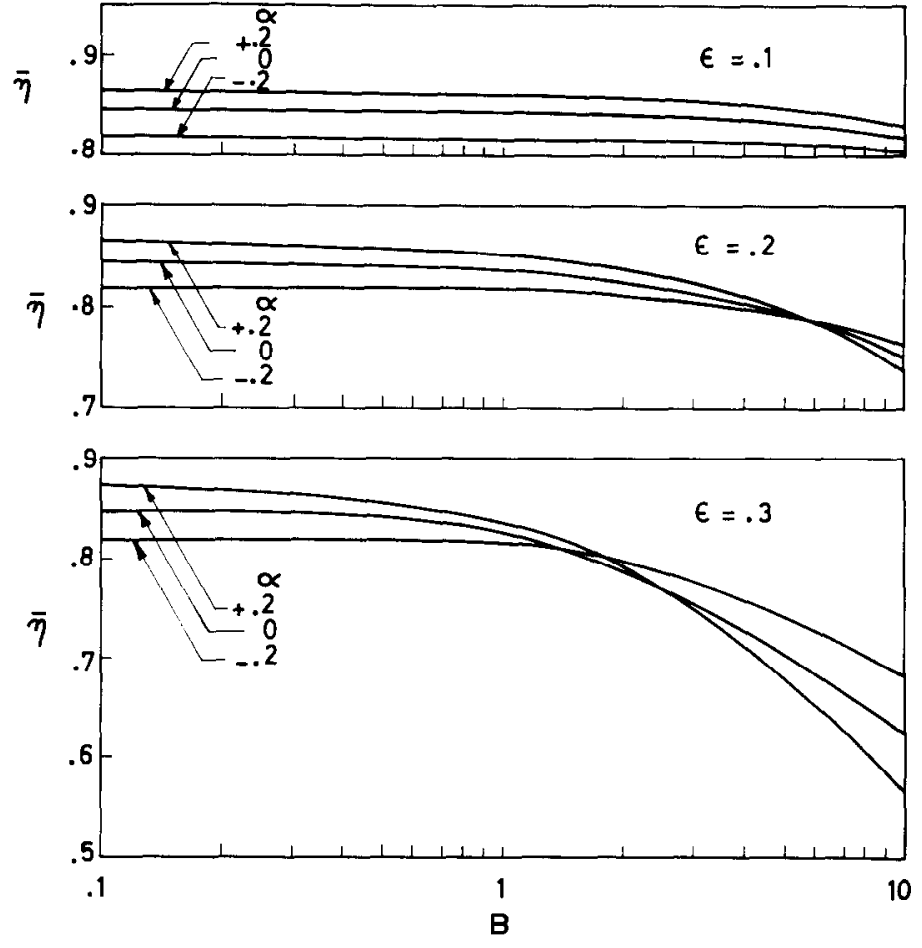

FIG. 6. Time-average fin efficiency: effect of $B, \alpha$ and $\varepsilon ; N=0.5, f(X)=\exp (X)$. 
heat loss; and (c) no surface radiation. Regarding assumption (a), the use of fins is economically justifiable only if the Biot numbers $B i(=h b / k)$ is less than 0.1 . This being so, the two-dimensional steady-state analysis of Wan and Tan [6] shows that the error in heat transfer rate with one-dimensional assumption is very small indeed. The other two assumptions can be relaxed without altering the analysis in substance. However, two additional parameters, one for tip heat loss and the other for surface radiation, would appear and make compact display of the results even more difficult.

The extension of the analysis to other fin geometries can be made in a straightforward manner.

\section{REFERENCES}

1. A. Aziz and T. Y. Na, Steady periodic heat transfer in fins of arbitrary profiles. (In press).

2. P. Razelos and K. Imre, The optimum dimensions of circular fins with variable thermal parameters, $J$. Heat Transfer 102, 420-425 (1980).

3. J. W. Yang, Periodic heat transfer in straight fins, J. Heat Transfer 94, 310-314 (1972).

4. R. G. Eslinger and B. T. F. Chung, Periodic heat transfer in radiating and convecting fins or fin arrays, $A I A A J I$. 17, 1134-1140 (1979).

5. T. Y. Na, Computational Methods in Engineering Boundary Value Problems, pp. 13-28. Academic Press, New York (1979).

6. L. Wan and W. C. Tan, Errors in one dimensional heat transfer analysis in straight and annular fins, J. Heat Transfer 95, 549-551 (1973).

\section{TRANSFERT THERMIQUE PERIODIQUE DANS DES AILETTES AVEC DES PARAMETRFS VARIABLES}

Résumé - On étudie à partir d'une analyse de perturbation, le transfert thermique périodique dans une ailette avec une conductivité thermique dépendent de la température et un coefficient de transfert thermique de la coordonnée. Le problème d'ordre zéro qui correspond au comportement stationnaire est résolu par une quasi-linéarisation. Une méthode de combinaison complexe est utilisée en liaison a vec un schéma numérique et non-itératif, pour résoudre les problèmes du premier et du second ordre. La nature non-linéaire du problème donne lieu à une composante non-oscillante dans le terme de second ordre qui cause un changement dans les valeurs moyennes de température et de flux thermique. Le sens de ce changement dépend du paramètre $\alpha$ de conductivité thermique. Si $\alpha>0$, la température moyenne est accrue tandis que le flux moyen de chaleur est diminué. Pour $\alpha<0$, l'effet est opposé. Des résultats détaillés sont présentés et discutés pour les effets des différents paramètres sur la distribution de la température, le flux moyen de chaleur et l'efficacité moyenne de l'ailette.

\section{PERIODISCHE WÄRMEÜBERTRAGUNG AN RIPPEN MIT VERÄNDERLICHEN THERMISCHEN PARAMETERN}

Zusammenfassung-Die periodische Wärmeübertragung durch eine Rippe mit temperaturbhängiger Wärmeleitfähigkeit und ortsbhängigen Wärmeübergangskoeffizienten wird mit Hilfe eines Störungsansatzes untersucht. Das Problem nullter Ordnung, das dem Verhalten der Rippe im stationären Zustand entspricht, wird durch Quasilinearisation gelöst. Eine Methode komplexer Kombination wird in Verbindung mit einem nichtiterativen numerischen Verfahren zur Lösung der Probleme erster und zweiter Ordnung benutzt. Die Nichtlinearität des Problems führt zu einer nichtoszillierenden Komponente im Glied zweiter Ordnung, die eine effektive Änderung der Mittelwerte von Temperatur und Wärmestrom zur Folge hat. Die Richtung der Änderung hängt vom dem Parameter $\alpha$ der Wärmeleitfähgkeit ab. Für $\alpha>0$ vermindert sich die mittlere Temperatur. Für $\alpha<0$ ist der Einflu $\beta$ umgekehrt. Ausführliche Ergebnisse, die die Einflüsse verschiedener Parameter auf die Temperaturverteilung die übertragene Wärme und den zeitlich gemittelten Rippenwirkungsgrad zeigen, werden mitgeteilt und besprochen.

\section{ПЕРИОДИЧЕСКИЙ РЕЖИМ ТЕПЛООБМЕНА РЕБЕР С ПЕРЕМЕННЫМИ ТЕПЛОВЫМИ ПАРАМЕТРАМИ}

Аннотация - На основе теории возмущений анализируется периодический режим конвективного теплообмена ребра, теплопроводность которого зависит от температуры, а коэффичиенг теплоотдачи - от координаты. В нулевом порядке. соответствующем стационарному состоянию ребра, задача решается методом квазилинеаризации. Для решения задач первого и второго порядков используется метод комплексной комбинации совместно с неитерационной численной схемой. В связи с нелинейным характером задачи в слагаемом второго порядка появляется неосциллируюшая компонента, что приводит к изменению средних значений температуры и интенсивности переноса тепла. Направление изменения зависит от параметра теплопроводности $\alpha$. При $x>0$ среднее значение температуры возрастает, а средиее значение интенсивности переноса тепла уменьшается. При $x<0$ наблюдается противоположный эффект. Получены подробные данные, характеризующие влияние различных параметров на распределение температуры, интенсивность теплоотдачи и среднюю по времени эффективность ребра. 